\title{
PDA-based Multifunctional Microfluidic Sensor System
}

\author{
Radislav A. Potyrailo, Andrew Leach, and William G. Morris \\ GE Global Research, 1 Research Circle, Niskayuna, NY, USA \\ Corresponding e-mail address: Potyrailo@crd.ge.com
}

\begin{abstract}
We demonstrate a personal data assistant (PDA)-based analytical platform that provides detection, fluid manipulation, computing, and communication capabilities for multi-functional chemical analysis. This multi-functionality is provided by integrating the PDA with a microfluidic system, solid sensing films, and a micro-pump operated by PDA. The applicability of our approach for chemical detection in water and air was illustrated using a built integrated circuit board with eight surface mounted light source-detector opto-pairs with peak emission at 560 and $630 \mathrm{~nm}$ for detection of absorbance, scatter, or luminescence from a sample or a sensing film. For chemical detection in gases, disposable sensing films were attached to the opto-pairs array though a light scattering layer. For chemical detection in liquids, a polydimethylsiloxane microfluidic channel network was built. The fluidic network consisted of sample reservoirs connected via $200 \mu \mathrm{m}$ wide, $100 \mu \mathrm{m}$ tall channels to a common mixing point. The system was capable of operating a sampling micro-pump for $10 \mathrm{~h}$.
\end{abstract}

Key words: personal data assistant (PDA), analytical platform, chemical analysis, microfluidic system, solid sensing films

\section{Introduction}

Existing sensors have long timelines from the concept to practical implementations [1]. The widely deployed commodity consumer products and their electronic components present an outstanding set of capabilities applicable for advanced sensors [2, 3].

Our group is developing approaches to implement such high-performance components and products for sensing. In particular, we have developed carbon dioxide gas sensors based on micromachined transducers with integrated piezoresistive readout [4], demonstrated multi-wavelength operation of optical disk drives for chemical and biological analysis [5], and developed wireless sensors for single-use biopharmaceutical manufacturing components [6].

In this study, we take advantage of massproduced personal data assistant (PDA) platform and integrate it with fluidic manipulation and optical detection components to produce wireless networked types of chemical sensors for gas and liquid analysis.

\section{Experimental}

An integrated circuit board was built with eight surface mounted light source-detector optopairs (TAOS, Plano, TX) with peak emission at 560 and $630 \mathrm{~nm}$ (Fig. 1) for detection of absorbance, scatter, or luminescence from a sample or a sensing film.

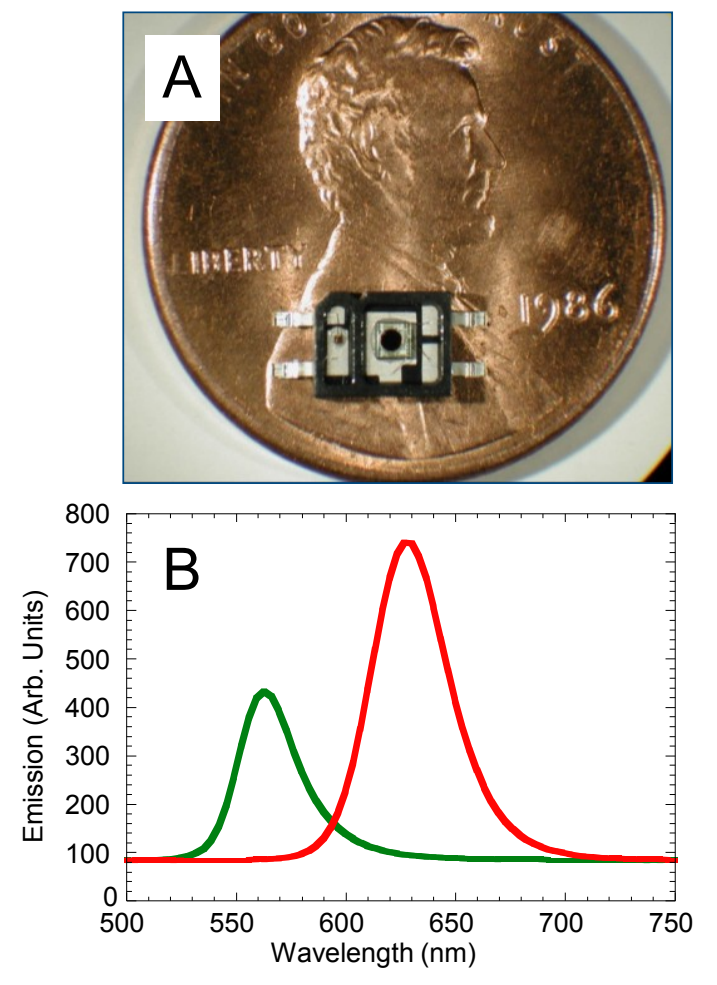

Fig. 1. Optical detection components for PDAbased multifunctional microfluidic sensor system: $(A)$ Example of a surface mounted light source-detector opto-pair. (B) Emission spectra of the light sources in the fabricated microfluidic chip. 
For chemical detection in gases, disposable sensing films were attached to the opto-pairs array though a light scattering layer. For chemical detection in liquids, a polydimethylsiloxane microfluidic channel network was built.

The fluidic network consisted of sample reservoirs connected via $200 \mu \mathrm{m}$ wide, $100 \mu \mathrm{m}$ tall channels to a common mixing point (Fig. 2A). A general view of the built PDA-based system is presented in Fig. 2B. The system was capable of operating a sampling micropump for $10 \mathrm{~h}$.

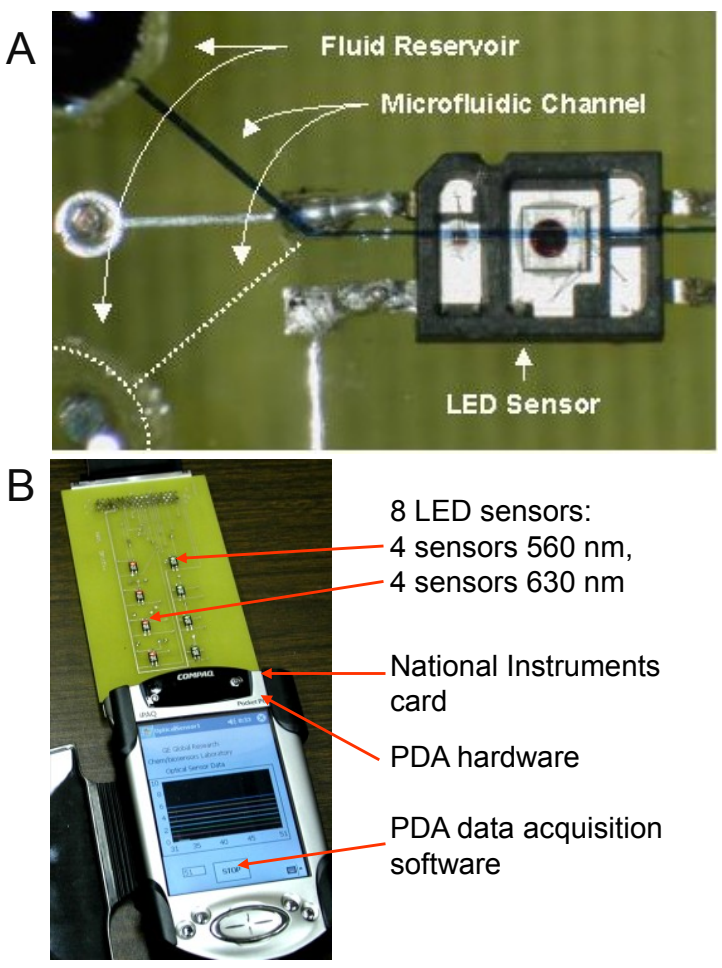

Fig. 2. System design: (A) Microfluidic channel network positioned above an opto-pair sensor on PDA. (B) General view of the built PDA-based system.

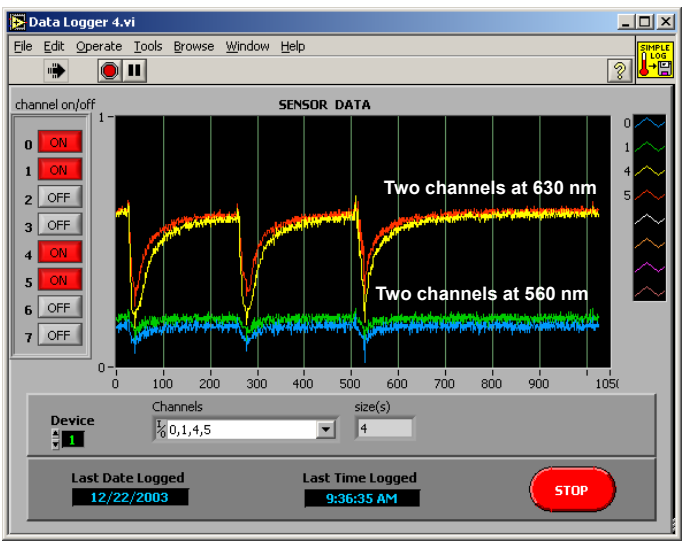

Fig. 3. Example of a control screen of the developed software to operate our developed PDAbased multifunctional microfluidic sensor system.

\section{Results and Discussion}

An example of a control screen of the developed software to operate our developed PDA-based multifunctional microfluidic sensor system is illustrated in Fig. 3. The software controlled the independent operation of the optical surface mounted 560-nm and 630-nm light source-detector opto-pairs and the sampling micro-pump.

For demonstration of chemical detection in water, initial validation was performed with varied levels of a colorimetric dye (Brilliant Blue) as shown in Fig. 4A. Monitoring of a model chemical reaction was demonstrated by following a protonation/deprotonation reaction process using a colorimetric $\mathrm{pH}$ sensitive dye (Bromophenol Blue) as shown in Fig. 4B.

For demonstration of chemical detection in air, a PDA-operated pump was utilized to transport air samples to sensing films on the integrated circuit board. In one demonstration, water vapor concentration was monitored using a Nafion / crystal violet sensing film (Fig. 5A). Ammonia vapor determinations were done with a Nafion/bromothymol blue sensing film (Fig. 5B).
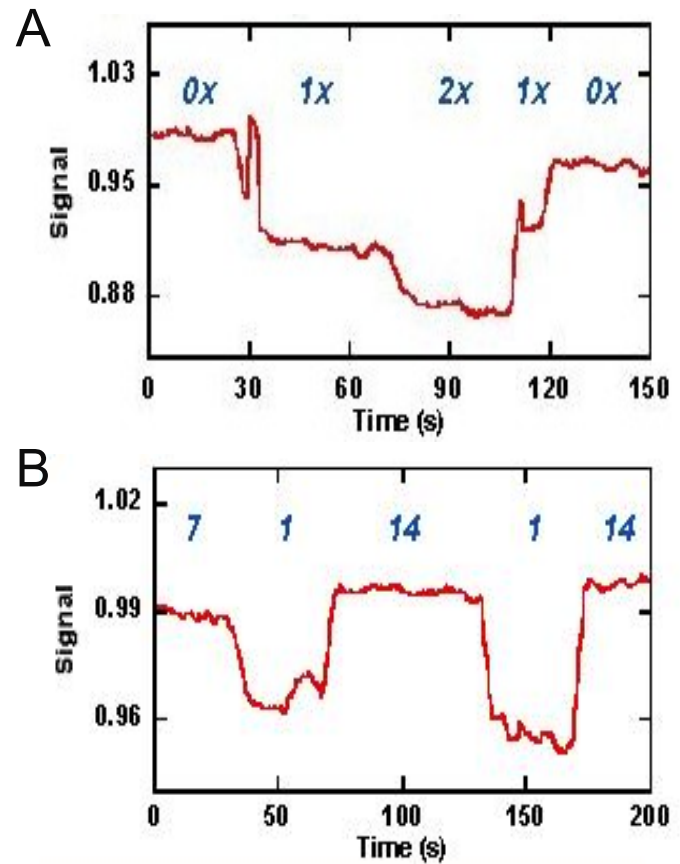

Fig. 4. Demonstration of PDA-based chemical detection in water. (A) Monitoring of changes in optical properties of liquids in microchannels with variable (blank, $1 x$, and $2 x$ ) concentrations of a colorimetric dye as an example. (B) Monitoring of chemical reactions in microchannels with protonation/deprotonation of a $\mathrm{pH}$ dye as an example. Numbers are $\mathrm{pH}$ values of a sample solution reacted with the dye. 

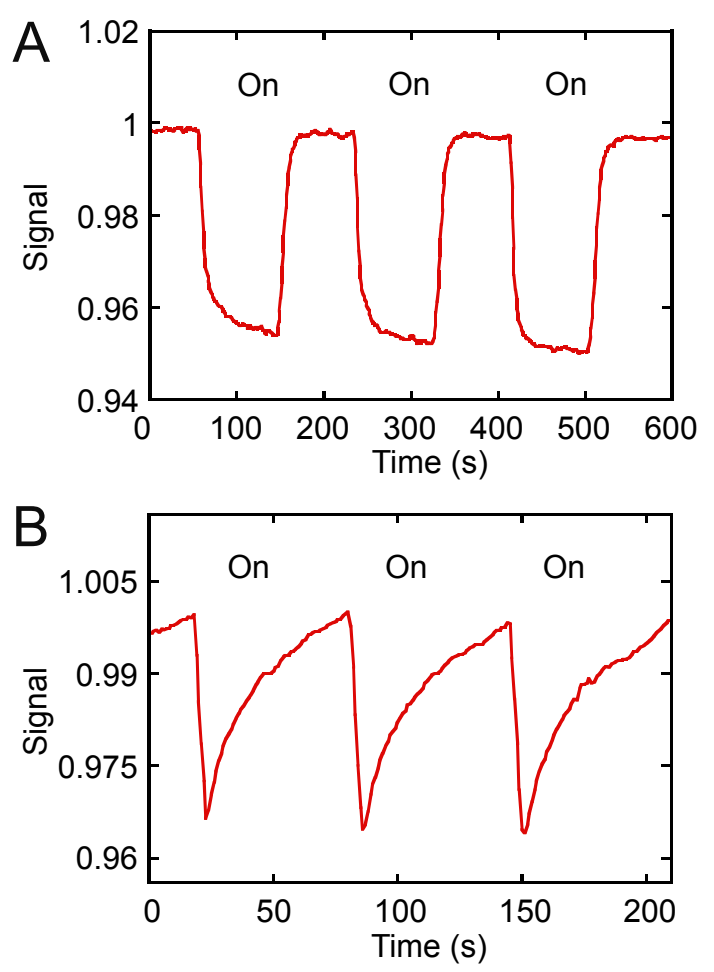

Fig. 5. Demonstration of PDA-based chemical detection in water. (A) Monitoring of water vapor using a Nafion / crystal violet sensing film. (B) Monitoring of ammonia vapor using a Nafion / bromothymol blue sensing film.

\section{Conclusions}

Developed microfluidic system provides numerous opportunities arising from the selfcontained and wireless nature of this analytical device. These opportunities are in the areas of analysis of water and other liquids and well as of analysis of air.

Because the personal data assistant devices are connected to the network, they can be utilized as wireless sensor nodes [7] for distributed chemical and biological detection.

\section{References}

[1] J. Janata, Principles of Chemical Sensors (Springer, New York, NY, ed. 2, 2009); ISBN 978-0-387-69930-1.

[2] R. Bjorklund, D. Filippini and I. Lundström, Automatic optimization of experimental conditions for fast evaluation of diagnostic tests using ubiquitous instrumentation, Sens. Actuators B, 134, 199-205 (2008); doi: 10.1016/j.snb.2008.04.037.

[3] J. W. Gardner, P. K. Guha, F. Udrea and J. A. Covington, CMOS interfacing for integrated gas sensors: A review, IEEE Sensors J., 10, 18331848 (2010); doi: 10.1109/JSEN.2010.2046409.
[4] R. A. Potyrailo, A. M. Leach, W. G. Morris and S. K. Gamage, Chemical Sensors Based on Micromachined Transducers with Integrated Piezoresistive Readout, Anal. Chem., 78, 56335638 (2006); doi: 10.1021/ac052086q.

[5] R. A. Potyrailo, W. G. Morris, R. Wroczynski, L. Hassib, P. Miller, B. Dworken, A. M. Leach, S. Boyette and $\mathrm{C}$. Xiao, Multi-wavelength operation of optical disk drives for chemical and biological analysis, Sens. Actuators B, 136, 203-208 (2009); doi:10.1016/j.snb.2008.10.071.

[6] R. A. Potyrailo, T. Wortley, C. Surman, D. Monk, W. G. Morris, M. Vincent, R. Diana, V. Pizzi, J. Carter, G. Gach, S. Klensmeden and H. Ehring, Passive multivariable temperature and conductivity RFID sensors for single-use biopharmaceutical manufacturing components, Biotechnol. Prog., 27, 875-884 (2011); doi: 10.1002/btpr.586.

[7] R. A. Potyrailo, C. Surman, N. N. Nagraj and A. Burns, Materials and Transducers Toward Selective Wireless Gas Sensing, Chem. Rev., 111, 7315-7354 (2011); doi: $10.1021 / \mathrm{cr} 2000477$ 